\title{
Numerical simulation of fault development in fold-and-thrust belt of Nepal Himalaya
}

\author{
D Chamlagain* and D Hayashi \\ Department of Physics and Earth Sciences, University of the Ryukyus, Nishihara, Okinawa, 903-0213, JAPAN \\ * To whom correspondence should be addressed.E-mail: dchamlagain@hotmail.com
}

The Himalaya, a fold-and-thrust belt on the northern margin of the Indian continent, is characterized by a series of foreland propagating thrust system. From north to south these are: the Main Central Thrust (MCT), the Main Boundary Thrust (MBT) and the Main Frontal Thrust (MFT) (Schelling and Arita 1991). These intracrustal thrusts are splay thrusts of the Main Himalayan Thrust (MHT), which marks the underthrusting of Indian lithosphere beneath the Himalayas and Tibet. Geodetic and microseismic data have revealed stress accumulation due to mid-crustal ramp, which acts as a geometrical asperity during interseismic period. The stress state and seismicity in the Himalaya is largely influenced by the nature and geometry of MHT. Further, structural and seismic data show segmentation and variation in geometry of the MHT in Nepal Himalaya. It is well understood that neotectonics and present-day seismicity of the Himalaya are largely controlled by its activity. Thus, it is essential to gain better understanding of deformation along different structural sections of Nepal Himalaya.

In the present study, we examined the state of stress in eastern, central and western Nepal Himalaya using 2D elastic finite element method under plane strain condition. We chose three structural cross-sections from east (Schelling and Arita 1991), central (Upreti and Le Fort 1999) and western (Upreti and Le Fort 1999) Nepal Himalaya. Detailed analysis of the mediumscale seismicity has shown the existence of several distinct clusters in eastern, central and western Nepal (Pandey et al. 1999). The projection of events on structural cross-sections reveals rounded shape in central Nepal where center is located at flat-ramp transition whereas in western Nepal cluster is elongated and nearly horizontal. The structural cross-sections used by our simulation represent these clusters as microseismic zones.

This study mainly focuses on applications of numerical modelling techniqueand the finite element method to compute stresses and faults as a function of rock layer properties, convergent displacement and boundary condition in the convergent tectonic environment of Nepal Himalaya. However, interpretation of the simulated models remains ambiguous to some extent because of the limitations of elastic modelling. Despite its limitations, our models still allow us comparison with geological, microseismic and geophysical data. The results of this simulation are compared with three cross-sections of eastern, central and western Nepal by using recordings of neotectonics and microseimicity of the area. The stress distribution pattern shows similarity in magnitude and orientation in east, central and western Nepal Himalaya. Compressive state of the stress is found in all models. The magnitude of principal stresses mainly depends upon rock layer properties and applied convergent displacement. With increasing convergent displacement, the magnitude of $\sigma_{1}$ increases and its axis rotates towards horizontal resulting thrust fault.

Failure analysis demonstrates realistic fault patterns on the profiles of Nepal Himalaya. We have successfully computed several active faults at their proper locations, which corresponds the field observations. Active faults both normal and thrust types are predicted in Lesser Himalaya, Siwalik and the frontal part of MFT. All models predict faulting to initiate at depth and to transmit to surface with increasing convergent displacement and finally propagate towards south. This is consistent with the sequence of thrust development in Himalayan fold-and-thrust belt. The distribution of simulated faults seems to associate with the major thrusts e.g. MBT and MFT forming north dipping imbricated zone as revealed by field study (e.g. Nakata 1989). For eastern and central Nepal, the simulated fault pattern is similar but for western Nepal thrust fault emerges in shallow depth under the same convergent displacement suggesting difference in geometry of MHT and convergence displacement. Moreover, we observed faults around the mid-crustal ramp, which shows the active nature of MHT. It could be attributed to interseismic stress accumulation around the flat-ramp-flat region. Thus, our models clearly indicate that present-day tectonic activities are mainly concentrated around the midcrustal ramp, MBT and MFT of the fold-and-thrust belt of Nepal Himalaya.

\section{References}

Nakata T. 1989. Active faults of the Himalaya of India and Nepal. Geol Soc Amer Spec Paper 232: 243-263

Pandey MR, RP Tandukar, JP Avouac, J Lave and J P Massot. 1995. Interseismic strain accumulation on the Himalayan crustal ramp (Nepal). Geophys Res Lett 22: 751-754

Schelling, D and K Arita. 1991. Thrust tectonics, crustal shortening, and the structure of the far eastern Nepal Himalaya. Tectonics 10(5): 851862

Upreti BN and P Le Fort. 1999. Lesser Himalayan crystalline nappes of Nepal: problems of their origin. In Macfarlane, A, R B Sorkhabi, and J Quade (eds) Himalaya and Tibet: Mountain Roots to Mountains top, Geol Soc Amer Spec Paper 328, 225-238 